\title{
A Comparative Study of the Reducing Activity of Leukocytes of Rodent and Human Blood ${ }^{1,2}$
}

\author{
ALBINA ANN YAKAITIS \\ Departments of Pathology and Anatomy, The University of Michigan, \\ Ann Arbor, Michigan
}

Formazan crystals resulting from the reduction of tetrazoles have been utilized in demonstrating the presence of reductase activity in leukocytes. Wachstein ('49) first noted formazan in polymorphonuclear cells of various human exudates, and later ('50) in cells of bone marrow, lymph nodes, and peripheral blood. In bone marrow suspensions the reacting cells were principally myelocytes, and occasionally, nucleated red blood cells and megakaryocytes, while in lymph node suspensions numerous lymphocytes showed evidence of reductase activity. In normal human blood, reacting cells were principally of the polymorphonuclear series and, in varying degrees, of the non-granulocytic series. After a study of the blood of various animals (rats, mice, guinea pigs, and rabbits) Wachstein concluded that the cells containing formazan were of the polymorphonuclear type.

Recently a new method was presented for studying the cytochemical activity of leukocytes (Yakaitis, '59). This method consisted of incubating peripheral blood in a white blood cell counting pipette with a buffered solution of 2-(p-iodophenyl)-3-(pnitrophenyl)-5-phenyltetrazolium chloride (hereafter designated as INT), spreading the incubated mixture on a slide, counterstaining, and studying the resulting preparation microscopically. In previous work the following was noted: (1) Blood from newborn mice has a low percentage of leukocytes with crystals of formazan; the mean percentages were less than 30 . (2) Blood from adult mice and rats had a higher percentage of leukocytes with formazan; more than $50 \%$ of the cells contained crystals. (3) Blood from mice belonging to the leukemia-suspectible AKR strain had a higher percentage of leukocytes with formazan than did leukocytes from blood samples of two resistant strains; $77 \%$ of the leukocytes contained formazan.

For the present investigation the pipette incubation method was utilized in a comparative study of the reducing ability of leukocytes from mice, white New Zealand rabbits, guinea pigs, and from human blood. The purpose of the study was, first, to note whether the high level of reductase activity noted in young adult mice and rats was similar to the histochemical pattern in blood of other rodents; secondly, to note whether human blood would show similar evidence of reductase activity; and, thirdly, to note which leukocytes would show crystalline evidence of reductase activity following this type of incubation.

\section{MATERIAL AND METHODS}

Peripheral blood from $14 \mathrm{BALB}_{\mathrm{f}} / \mathrm{cJax}$ mice, 24 laboratory New Zealand white rabbits, 14 guinea pigs, and 36 human donors was used. The blood was procured from the tip of the tail of the mice, from the ear veins of the guinea pigs and rabbits, and from finger pricks of the human donors. As in the previous study (Yakaitis, '59) the incubating solution contained the following: $6 \mathrm{mg}$ of INT (Dajac Laboratories ); $2 \mathrm{ml}$ of $\mathrm{N}, \mathrm{N}$-dimethylformamide (Eastman Organic Chemicals); and $2 \mathrm{ml}$ of $\mathrm{M} / 15$ phosphate buffer $\mathrm{pH}$ 7.5. The solution was used immediately after mixing for one group of animals (BALB ${ }_{f}$ ) cJax-6M $-6 \mathrm{M}_{2}$ ); for the remaining groups the solution was allowed to reach room temperature before being used. Blood was

${ }^{1}$ This study was supported in part by a grant to The University of Michigan Cancer Research Institute (Project 22, no. 36828) from the American Cancer Society.

2 Part of this report was presented from the platform at the Seventh International Anatomical Congress, New York City, N. Y., April 13, 1960. 
drawn into a white blood cell counting pipette to the 4 mark; the incubating solution was then drawn into the pipette until the mixture filled the expanded portion. The pipette was agitated in a horizontal plane by a clinical shaker for 15 minutes at room temperature $\left(233 / 4-241 / 4^{\circ} \mathrm{C}\right)$. The incubated mixture was then spread on a slide, chilled on ice, and dried at a temperature of $8-11^{\circ} \mathrm{C}$. The dried preparation was counterstained with a $50 \%$ solution of Harris' hematoxylin for 45 minutes, rinsed in tap water, and mounted in glycerogel.

The percentage of cells containing formazan crystals was determined by counting 700 cells under oil immersion. The data were analyzed using the method described by Goulden ('39) and the table of " $t$ " values of Fisher and Yates ("48). White blood cell counts and smears were done simultaneously with the preparation of the enzyme reaction.

\section{RESULTS}

\section{Semi-quantitative observations}

Of the 4 species studied, the blood of $\mathrm{BALB}_{\mathrm{f}}$ mice had the highest percentage of leukocytes with crystalline evidence of reductase activity (table 1 and fig. 1). A sample from one of the 7 female mice showed $81.6 \%$ active cells; the mean percentage for the females was 72.3 and for the males 68.0. When subjected to statistical analysis, the figures for males and females were not found to be significantly different.

The $6 \mathrm{M}_{1}$ and $6 \mathrm{M}_{2}$ in table 1 and figure 1 represent two different sets of prepara- tions from 6 male mice. Blood from the $6 \mathrm{M}_{1}$ set was incubated after the buffered INT solution was allowed to reach room temperature; for the $6 \mathrm{M}_{2}$ set, blood was taken from the same 6 mice and incubated immediately after the solution was mixed while the temperature of the solution was above room temperature due to the heat of the solution. In the first set $66.3 \%$ of the leukocytes contained formazan while in the second set, $78.2 \%$ of the cells reacted. The difference was statistically significant; therefore, all reactions thereafter were carried out after the INT had reached room temperature.

In the three remaining species studied, the reductase activity of leukocytes did not reach the high level noted in the mice. The percentage of reacting cells in the blood of the 15 female rabbits was 25.3

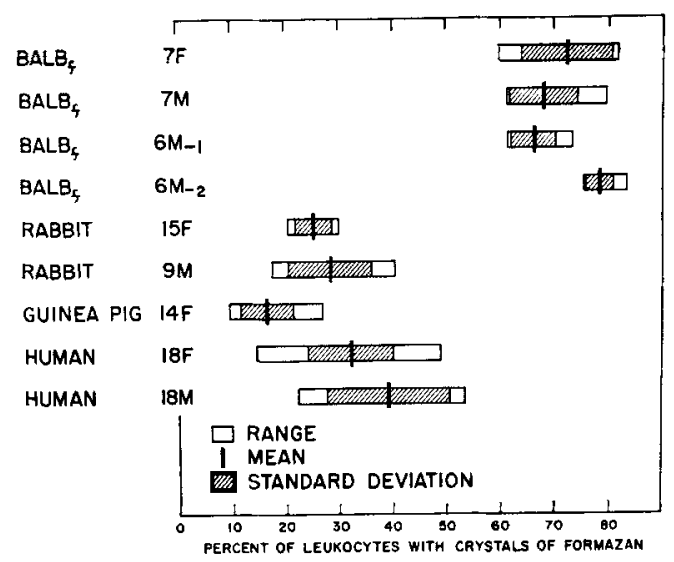

Fig. 1 Reductase activity of leukocytes as determined by the percentage of cells containing crystalline evidence of the reduction of INT.

TABLE 1

The percentage of leukocytes showing crystalline evidence of reductase activity following incubation with a buffered solution of INT

\begin{tabular}{lccc}
\hline \multicolumn{1}{c}{ Group } & $\begin{array}{c}\text { Number } \\
\text { and sex }\end{array}$ & $\begin{array}{c}\text { Range of } \\
\text { positive } \\
\text { reaction } \\
(\% \text { of } 700)\end{array}$ & $\begin{array}{c}\text { Mean of } \\
\text { positive } \\
\text { reaction } \\
(\% \text { of } 700)\end{array}$ \\
\hline BALB $_{\mathrm{f}}$ mice & $7 \mathrm{~F}$ & $59.8-81.6$ & $72.3 \pm 8.3^{1}$ \\
BALB $_{\mathrm{f}}$ mice & $7 \mathrm{M}$ & $61.2-79.8$ & $68.0 \pm 6.2$ \\
BALB $_{\mathrm{f}}$ mice & $6 \mathrm{M}_{\mathrm{1}}$ & $61.2-73.4$ & $66.3 \pm 4.3$ \\
BALB $_{\mathrm{f}}$ mice & $6 \mathrm{M}$ & $75.4-83.4$ & $78.2 \pm 2.7$ \\
Rabbits & $15 \mathrm{~F}$ & $20.4-30.0$ & $25.3 \pm 3.3$ \\
Rabbits & $9 \mathrm{M}$ & $\mathbf{1 7 . 5}-40.2$ & $28.3 \pm 7.7$ \\
Guinea pigs & $14 \mathrm{~F}$ & $9.6-27.0$ & $16.7 \pm 4.8$ \\
Human beings & $18 \mathrm{~F}$ & $14.6-48.8$ & $32.1 \pm \mathbf{8 . 7}$ \\
Human beings & $18 \mathrm{M}$ & $22.4-53.4$ & $39.1 \pm 11.4$ \\
\hline
\end{tabular}

1 Mean with standard deviation. 
and of the 9 male rabbits 28.3. This amount of leukocytic activity was significantly lower than the amount noted for the mice $(P<0.001)$. The range and standard deviation were small for the female rabbits and large for the male rabbits.

Of all the species studied, the guinea pigs had the lowest percentage of leukocytes with crystals of formazan. One sample had only $9.6 \%$ of the cells showing evidence of reduction. The mean for the guinea pigs was only $16.7 \%$. This amount of activity was significantly lower than the amount noted for both female mice $(\mathrm{P}<$ $0.001)$ and the female rabbit $(P<0.001)$.

Leukocytes of blood from human donors showed a wide range of reductase activity. In one sample of blood from a female donor only $14.5 \%$ of the cells contained formazan; on the other hand, in another sample of blood from a male donor $53.4 \%$ of the leukocytes were positive for reductase activity. The mean for the female samples was $32.1 \%$ and for the male samples $39.1 \%$. These percentages were significantly lower than those noted for the mice ( $\mathrm{P}<0.001$ for both males and females); and were significantly higher than those noted for the guinea pigs ( $\mathrm{P}<$ $0.001)$ and the rabbits $(P<0.01$ for the females and $P<0.02$ for the males ).

\section{Histologic observations}

Formazan was most prominent in the

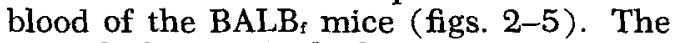
crystals formed by leukocytes of the adult mouse were dark red in color and needlelike in appearance. The length of the needles was usually greater than the diameter of the nucleus of the cell. Not only did mouse blood contain a greater percentage of reacting cells, but the number of crystals per cell was greater in mouse blood samples than in other blood samples. In a large number of cells the crowding of crystals obscured the form of the nucleus (fig. 2). Crystals were present in both granulocytic and non-granulocytic leukocytes (fig. 5); this was the case in the blood of all species studied. Intricate crystalline forms were most often associated with cells of the non-granulocytic series (cf. figs. 4,5); such forms were frequent in mouse blood.
Formazan crystals in the leukocytes of rabbit blood (figs. 6,7 ) usually were fewer in number per cell than in leukocytes of mouse blood. The crystals were usually needle-like as in the mouse preparations but were not consistently as long; needles measuring less than the diameter of the nucleus were frequent in rabbit preparations. Intricate forms were rare in rabbit blood.

In guinea pig blood crystals of formazan were short, thick, and few in number (figs. $8,9)$. Intricate configurations similar to those observed in mouse blood were not observed in any of the guinea pig samples.

In human blood, crystals showed a great variation in size and number. Some samples contained cells with predominantly long crystals; some had short crystals; while other samples had crystals of varying lengths. Long crystals, when present, were associated usually with lymphocytes (fig. 10) and eosinophils (fig. 11). Polymorphonuclear leukocytes sometimes had long crystals, but more often the crystals associated with these cells were short (fig. 12).

The lymphocyte shown in figure 10 is from a blood sample in which most of the reacted non-granulocytes contained exceptionally long crystals. The monocyte in figure 13 is from the blood of the same donor; however, in the process of preparing this particular sample, an air bubble entered the pipette and it was noted with interest that only $10.2 \%$ of the cells reacted. This was in contrast to the $30.4 \%$ noted in the former preparation when no air was in the pipette.

Eosinophils could be distinguished from neutrophils in human blood due to the larger size of the cell and to the different appearance of the cytoplasm (fig. 11). The cytoplasm had either a yellow granularity or a grayish hue. The cytoplasm of the eosinophil in figure 11 had a distinguishing grayish cast. The differential for this particular sample revealed an eosinophil count of 7 . This count corresponded to the percentage of cells in the preparation which were considered eosinophils. The donor had a history of hay fever.

\section{DISCUSSION}

This study demonstrates the variability in the ability of leukocytes of different 
species to reduce tetrazolium. The pronounced ability of leukocytes of mice to form formazan was not found to be the prevalent cytochemical pattern for other rodents. Crystal formation was low in the blood of guinea pigs and was slightly higher in the blood of rabbits.

Reductase activity was not restricted to one type of leukocyte but was noted in cells of both the granulocytic and non-granulocytic series. This differs from the observations of Wachstein ('50) who noted activity in the polymorphonuclear cells of the blood of various rodents but not in other leukocytes. A number of reasons may be offered to account for this difference. (1) Wachstein used a longer procedure which involved heparinization and centrifugation. During this interval, the non-granulocytes may have lost much of their reducing ability. (2) A tetrazole was used which forms fine granules when reduced. Due to the small size of these granules and to the relatively limited amount of cytoplasm in lymphocytes, reacted cells may not have been readily discernible. (3) Wachstein did not try counterstaining and admittedly found identification of cells a difficult problem. Under such circumstances reacted lymphocytes might have been overlooked.

Leukocytes of human blood did not show pronounced reductase activity following incubation at room temperature. A wide range in activity was noted; from 14.6 to $53.4 \%$ of the leukocytes contained formazan. Wachstein, in his study, noted that between 62 and $84 \%$ of the white blood cells of normal human blood showed evidence of reductase activity. This discrepancy in percentages might be due to the difference in temperature in the procedures used. Blood was incubated at $37^{\circ} \mathrm{C}$ in Wachstein's investigation while in the present work the reaction was carried out at room temperature. If the incubating solution and the subsequent incubation period had been at $37^{\circ} \mathrm{C}$, the data probably would have been similar to that of Wachstein. However, the primary purpose of this experiment was not to note the extent of leukocytic activity at body temperature but rather to make a comparative study of the reducing activity of leukocytes of different animals. If the present experiment had been carried out at a higher temperature, the percentages would undoubtedly have been greater; however, the species differences noted at the higher temperature would probably have been comparable to those noted at the lower temperature.

Differences in size and shape of crystals were noted in blood samples that had been incubated at room temperature. Crystals were usually long and slender in the blood of mice, short and thick in the blood of guinea pigs, and variable in the blood of human donors. In human blood, long needles usually were associated with non-granulocytic cells and eosinophils. Whether incubation at higher temperatures would increase the length and complexity of the crystalline forms in less reactive specimens has not been determined.

The macro-crystal-forming monotetrazole INT was used for the present study because rapid recognition of reacting cells was desirable. However, tetrazoles which form fine crystalline deposits would be more suitable for studies in which precise intracellular localization of activity is desired. Granule-forming tetrazoles such as 2,2'-di-p-nitrophenyl-5, 5'-diphenyl-3,3'(3,3'-dimethoxy-4,4'-biphenylene)- ditetrazolium chloride (Nitro-BT) (De Souza and Kothare, '59) and pp'diphenylene bis 2(3,5-diphenyl tetrazolium chloride (NNT) (Wachstein, '50) have been used with hematological material although precise localization was not the purpose of the studies. In various other tissues, however, dehydrogenase activity has been traced to intramitochondrial elements. Some investigators (Sedar and Rose, '59; Barrnett, Karmarkar and Seligman, '59; Karmarkar, Barrnett, Nachlas and Seligman, '59) have described deposits of diformazan as appearing on the cristae and external membranes of mitochondria of myocardial, hepatic, and renal cells. Other investigators (Pearse, Scarpelli and Hess, '60) have described deposits of monoformazan as appearing in the form of intramitochondrial dots in hepatic and myocardial cells and suggested that these deposits were separated by areas of quiescence. Whether dehydrogenase activity in leukocytes is intramitochondrial has yet to be demonstrated. 


\section{SUMMARY}

A comparative study was made of the reductase activity of leukocytes of mice, guinea pigs, rabbits, and of human blood following incubation at room temperature in a pipette with the tetrazole INT.

It was noted that leukocytes of mice showed the greatest amount of reductase activity, that leukocytes of rabbits and human donors showed an intermediate amount of activity, and that leukocytes of guinea pigs showed the least amount of activity.

Crystals of formazan were usually long and slender in leukocytes of mice; short, thick, and sparse in leukocytes of guinea pigs; and exhibited great variation in leukocytes of human blood. In human blood crystals were usually long in eosinophils and short and sparse in other leukocytes; in some specimens long crystals were associated with non-granulocytic cells.

Amount of reductase activity, therefore, was observed to vary between different species, between leukocytes, and between different human donors.

\section{ACKNOWLEDGMENTS}

The author wishes to express her sincere thanks to Mrs. Majorie Nakamura and Miss Cecile Le Bouar for their technical assistance.

\section{LITERATURE CITED}

Barrnett, R. J., S. S. Karmarkar and A. M. Seligman 1959 The use of ditetrazolium salts as reagents for the demonstration of the sites of dehydrogenase activity with the electron microscope. Anat. Hec., 133: 360 (abstract).

De Souza, E. J., and S. N. Kothare 1959 A method for the cytochemical demonstration of succinic dehydrogenase in human leucocytes. J. Histochem. Cytochem., 7: 77-79.

Fisher, R. A., and F. Yates 1948 Statistical Tables. Hafner Publishing Co., New York, p. 32.

Goulden, C. H. 1939 Methods of Statistical Analysis. John Wiley and Sons, New York, pp. $40-41$.

Karmarkar, S. S., R. J. Barrnett, M. M. Nachlas and A. M. Seligman 1959 Synthesis of $p$ nitrophenyl substituted tetrazolium salts containing iodine and other groups. J. Am. Chem. Soc., 81: 3771-3775.

Pearse, A. G. E., D. G. Scarpelli and R. Hess 1960 A cytochemical study of the dehydrogenase of mitochondria and mitochondrial particulates by a monotetrazolium-cobalt chelation method. J. Biophys. Biochem. Cytol., 7: 243249.

Sedar, A. W., and C. G. Rosa 1959 Further studies on the localization of succinic dehydrogenase activity with the electron microscope. Anat. Rec., 133: 428, (abstract).

Wachstein, M. 1949 Reduction of potassium tellurite by living tissues. Proc. Soc. Exp. Biol. Med., 72: 175-178.

1950 Histochemical demenstration of reducing activity in normal and !eukemic blood and bone marrow cells. Ibid., 73: 306-308.

Yakaitis, A. A. 1959 The relationship of age, strain, and species to the reducing activity of leukocytes. Blood, 14: 1033-1039. 
PLATE 1

EXPLANATION OF FIGURES

Photomicrographs of formazan in leukocytes from rodent and human blood. Counterstained with hematoxylin.

2 Three positive lymphocytes and one unidentifiable positive leukocyte from BALB $_{\mathfrak{f}}$ male. Reactivity $60.2 \%$.

3 Two of the positive lymphocytes in figure 2 at higher magnification.

4 Lymphocyte with intricate configuration of crystals from BALB ${ }_{f}$ male. Reactivity $64.8 \%$.

5 Polymorphonuclear leukocyte from same preparation as in figure 4.

6 Large Iymphocytes from a male rabbit. Reactivity $30.4 \%$.

7 Polymorphonuclear leukocyte from a male rabbit. Reactivity $24.8 \%$.

8 Lymphocyte from a female guinea pig. Reactivity $9.6 \%$.

9 Polymorphonuclear leukocyte from same preparation as in figure 8.

10 Lymphocyte from blood of 30-year-old human female donor. Reactivity $30.4 \%$.

11 Eosinophil from blood of 33-year-old human male donor. Reactivity $22.4 \%$.

12 Polymorphonuclear leukocyte from blood of 31-year-old human male donor. Reactivity $30.2 \%$.

13 Monocyte from same donor as in figure 10. Reactivity $10.2 \%$. 

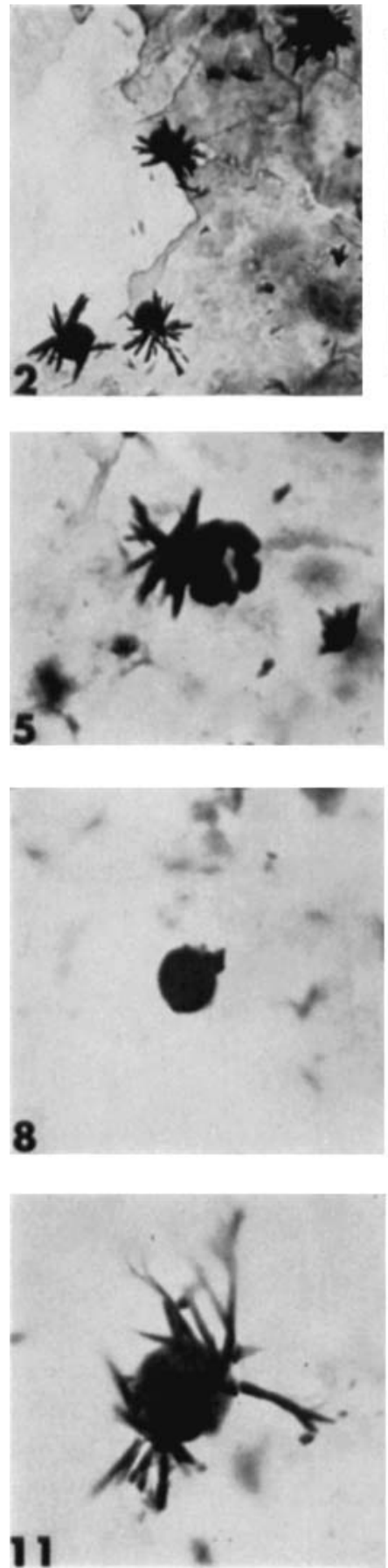
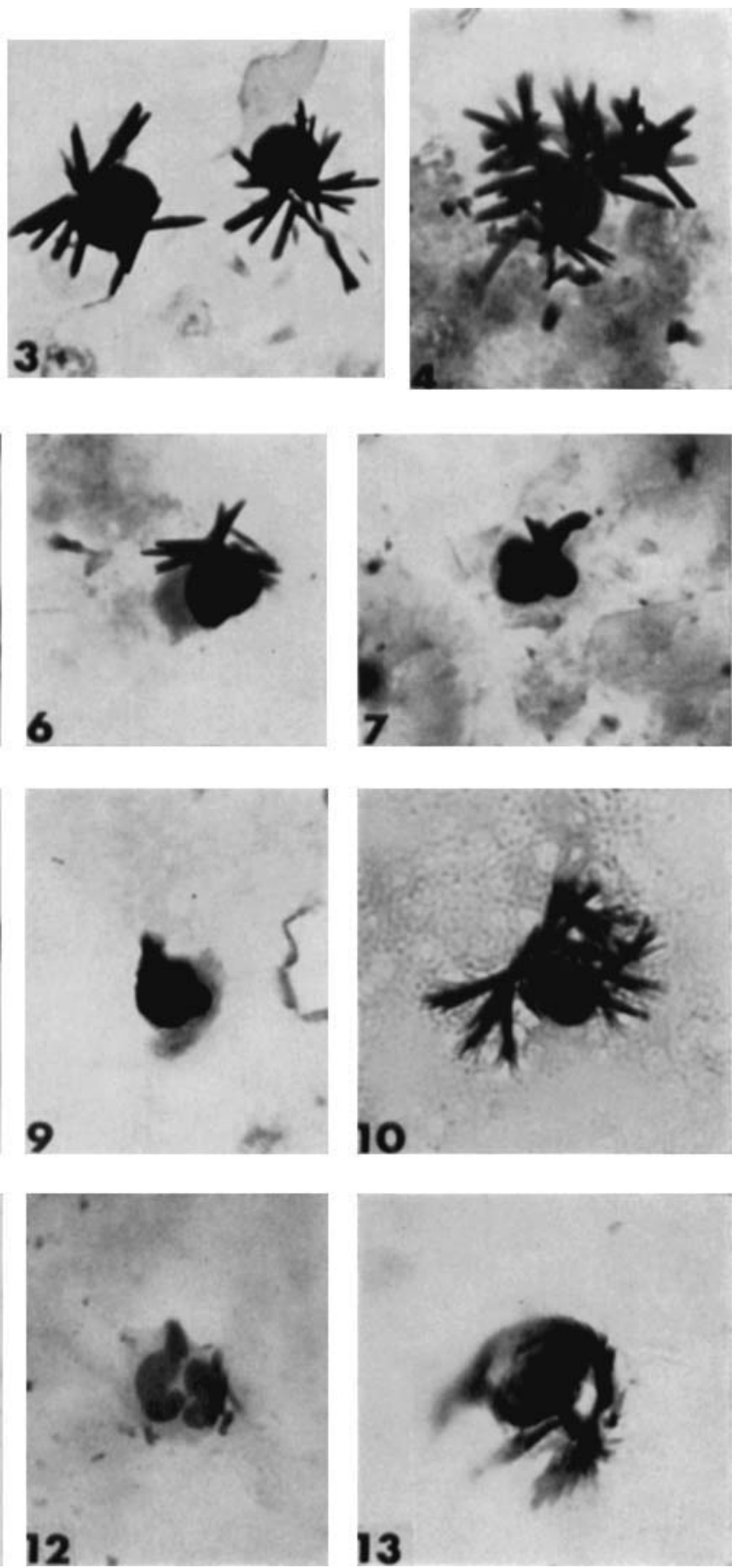